\title{
Production of the polyketide 6-deoxyerythronolide B in the heterologous host Bacillus subtilis
}

\author{
Jana Kumpfmüller ${ }^{1,4} \cdot$ Karen Methling $^{2} \cdot$ Lei Fang $^{3} \cdot$ Blaine A. Pfeifer $^{3} \cdot$ Michael Lalk $^{2}$. \\ Thomas Schweder ${ }^{1}$
}

Received: 5 May 2015 /Revised: 28 August 2015 / Accepted: 6 September 2015 /Published online: 2 October 2015

(C) The Author(s) 2015. This article is published with open access at Springerlink.com

\begin{abstract}
Polyketides, such as erythromycin, are complex natural products with diverse therapeutic applications. They are synthesized by multi-modular megaenzymes, so-called polyketide synthases (PKSs). The macrolide core of erythromycin, 6-deoxyerythronolide $\mathrm{B}$ (6dEB), is produced by the deoxyerythronolide $\mathrm{B}$ synthase (DEBS) that consists of three proteins each with a size of 330-370 $\mathrm{kDa}$. We cloned and investigated the expression of the corresponding gene cluster from Saccharopolyspora erythraea, which comprises more than $30 \mathrm{~kb}$, in Bacillus subtilis. It is shown that the DEBS genes are functionally expressed in B. subtilis when the native eryAI-III operon was separated into three individual expression cassettes with optimized ribosomal binding sites. A synthesis of $6 \mathrm{dEB}$ could be detected by using the acetoininducible aco $A$ promoter and a fed-batch simulating EnBase-cultivation strategy. B. subtilis was capable of the secretion of $6 \mathrm{dEB}$ into the medium. In order to improve the
\end{abstract}

Electronic supplementary material The online version of this article (doi:10.1007/s00253-015-6990-6) contains supplementary material, which is available to authorized users.

Thomas Schweder

schweder@uni-greifswald.de

1 Pharmaceutical Biotechnology, Institute of Pharmacy, Ernst-Moritz-Arndt-University, Felix-Hausdorff-Str. 3, 17489 Greifswald, Germany

2 Institute of Biochemistry, Ernst-Moritz-Arndt-University, Felix-Hausdorff-Str. 4, 17489 Greifswald, Germany

3 Department of Chemical and Biological Engineering, State University of New York at Buffalo, 904 Furnas Hall, Buffalo, NY 14260-4200, USA

4 Present Address: Department of Biomolecular Chemistry, Leibniz Institute for Natural Product Research and Infection Biology, HKI, Beutenbergstr. 11a, 07745 Jena, Germany
$6 \mathrm{dEB}$ production, several genomic modifications of this production strain were tested. This included the knockout of the native secondary metabolite clusters of $B$. subtilis for the synthesis of surfactin $(26 \mathrm{~kb})$, bacillaene $(76 \mathrm{~kb})$, and plipastatin $(38 \mathrm{~kb})$. It is revealed that the deletion of the $p r p B D$ operon, responsible for propionyl-CoA utilization, resulted in a significant increase of the $6 \mathrm{dEB}$ product yield when exogenous propionate is provided. Although the presented B. subtilis $6 \mathrm{dEB}$ production strain is not competitive with established Escherichia coli $6 \mathrm{dEB}$ production strains, the results of this study indicate that $B$. subtilis is a suitable heterologous host for the secretory production of a complex polyketide.

Keywords Bacillus subtilis · Deoxyerythronolide B synthase $\cdot$ Heterologous expression $\cdot$ Polyketide $\cdot$ aco $A$ promoter $\cdot$ Metabolic engineering

\section{Introduction}

The broad-spectrum antibiotic erythromycin, produced by the actinomycete Saccharopolyspora erythraea, is a well-studied representative of a class of complex natural products called polyketides (Corcoran 1981). Its macrolide core, 6deoxyerythronolide $\mathrm{B}(6 \mathrm{dEB})$, is synthesized by a polyketide synthase (PKS) that has emerged as the prototypical modular megasynthase (Khosla et al. 2007).

In general, PKSs can assemble complex biomolecules from simple building blocks such as malonyl coenzym A (malonylCoA), methylmalonyl-CoA, and propionyl-CoA through an assembly line thiotemplate mechanism (Cane and Walsh 1999). As a result of the variety of number and type of incorporated units in combination with the possible partial or complete reduction of each keto-function and further (also postenzymatic) modifications of the metabolite, this group of 
natural products shows an enormous degree of structural diversity. This in turn results in the extraordinary variety of biological properties and is the reason for the significance of this group, especially for pharmaceutical applications.

Unfortunately, natural sources can in many cases not cover the increasing demand for new bioactive natural products (Koehn and Carter 2005). Due to the structural complexity of polyketides, synthetic routes are precluded and the development of fermentation processes is necessary to allow sufficient production for pre-clinical and clinical studies. Quite often, success is closely linked with the selection of a suitable surrogate host. But, for heterologous polyketide biosynthesis, three challenges have to be addressed. First, the entire gene cluster needs to be functionally transferred. Second, the proteins have to be expressed, correctly folded, and posttranslationally modified. To this purpose, a universal phosphopantetheinyl transferase (PPTase) is required for pantetheinylation and thus activation of the PKS (Lambalot et al. 1996). Third, metabolic building blocks must be available. For example, the corresponding gene cluster for $6 \mathrm{dEB}$ synthesis comprises three genes of approximately $10 \mathrm{~kb}$ (eryAI-III). They encode for three large proteins, denoted DEBS1, DEBS2, and DEBS3, that show a size of 330$370 \mathrm{kDa}$ each and form an enzymatic complex. Along this protein complex, there are 28 active sites that are precisely arranged and responsible for the stepwise combination and modification of one propionyl-CoA primer unit and six $(2 S)$ methylmalonyl-CoA extender units (Fig. S1 in the Supplementary Material) (Khosla et al. 2007). Furthermore, with regard to the industrial production of drugs, many safety requirements which are regulated and controlled by the European Medicine Agency (EMA) or the Food and Drug Administration (FDA) have to be considered.

The Gram-positive, non-pathogenic strain Bacillus subtilis can fulfill these safety requirements as it owns the Generally Recognized As Safe (GRAS) status and the Qualified Presumption of Safety (QPS) certification (Leuschner et al. 2010; Sietske de Boer and Diderichsen 1991). Due to the absence of lipopolysaccharides on the outer cell membrane, which are a typical feature of Gram-negative hosts such as Escherichia coli and act as endotoxins, the downstream process is simplified and thus less cost intensive (Petsch and Anspach 2000). Furthermore, because of its natural ability to secrete peptides into the culture environment, which also facilitates downstream processing, $B$. subtilis is one of the most important strains for industrial enzyme production (van Dijl and Hecker 2013).

For heterologous production of secondary metabolites, it is especially noteworthy that $B$. subtilis, in contrast to $E$. coli, is a natural producer of several bioactive compounds (Stein 2005). The antibiotically effective bacillaene, which is synthesized via a PKS/non-ribosomal peptide synthetase (NRPS)-hybrid pathway, is one representative (Patel et al. 1995; Butcher et al.
2007). Two other examples are the non-ribosomal lipopeptide surfactin (Arima et al. 1968; Nakano et al. 1991) and plipastatin (Tsuge et al. 2007) with antimicrobial activities. Furthermore, with the secretory production of the peptide antibiotic bacitracin from Bacillus licheniformis (Eppelmann et al. 2001) as well as the cyclohexadepsipeptide enniatin from Fusarium oxysporum showing various antimicrobial effects (Zobel et al. 2015), the suitability of B. subtilis as a heterologous host for non-ribosomal peptide-type compounds could already be demonstrated.

To evaluate the suitability of $B$. subtilis as a heterologous host for the engineered biosynthesis of polyketides, we chose the already mentioned and well-investigated macrolide 6dEB as a model compound. Since this metabolite needs to be activated by several post-PKS modifications, it does not show any antibiotic effect that could inhibit the host. Furthermore, although heterologous production was already demonstrated in Streptomyces coelicolor (Kao et al. 1994) and E. coli (Pfeifer et al. 2001, 2002), there was an interest in extending the list of heterologous hosts further in anticipation of future biosynthetic efforts which may benefit from the capabilities of B. subtilis.

\section{Materials and methods}

\section{General information}

Unless stated otherwise, all chemicals were purchased from Roth (Karlsruhe, Germany) at the highest purity available and were used without further purification. Oligonucleotides (listed in Table S1 in the Supplementary Material) were synthesized and provided by Life Technologies (Darmstadt, Germany). All plasmids and strains used in this study are listed in Tables 1 and 2, respectively. Relevant translational and transcriptional elements of the native and modified eryAI-III gene cassettes are summarized in Table 3. All cloning procedures were carried out in E. coli DH10B (Invitrogen, Darmstadt, Germany) [F- endA1 recA1 galE15 galK16 nup G rpsL $\Delta$ lacX74 $\Phi 80$ lacZAM15 araD139 $\Delta$ (ara,leu) 7697 mcrA $\Delta(m r r-h s d R M S$ - $m c r B C) \lambda$-]. Restriction enzymes and other DNA-modifying enzymes were used as specified by the supplier (New England Biolabs, Frankfurt, Germany). PCR products were purified with the High Pure PCR Product Purification Kit (Roche, Mannheim, Germany). Plasmid isolation was performed using the High Pure Plasmid Isolation Kit (Roche, Mannheim, Germany). For gel extraction, the QIAquick Gel Extraction Kit from Qiagen (Hilden, Germany) was used. Recombinant $B$. subtilis strains were verified by colony PCR as previously described (Kumpfmüller et al. 2013). All plasmid constructs (see Supplementary Material) and chromosomal integrations were verified by sequencing carried out by Eurofins Genomics (Elbersberg, Germany). 
Table 1 Plasmids used in this study

\begin{tabular}{|c|c|c|}
\hline Plasmid & Function & Reference \\
\hline P1394 & Cosmid carrying wild-type eryAI-III-cluster in pWE13 & $\begin{array}{l}\text { Cosmid library of the Peter Leadlay } \\
\text { lab }^{\mathrm{a}}\end{array}$ \\
\hline $\begin{array}{l}\text { pAMY-lox- } \\
\text { SSS }\end{array}$ & Integration of genes into the $a m y E$ locus with lox-SSS-cassette & Kumpfmüller et al. (2013) \\
\hline pAMY-Spec & Integration of genes into the $a m y E$ locus with remaining Spec ${ }^{\mathrm{R}}$-cassette & Kumpfmüller et al. (2013) \\
\hline pAMY-SSS & Integration of genes into the $a m y E$ locus with SSS-cassette & Kumpfmüller et al. (2013) \\
\hline pJET-lox-SSS & Source of lox-SSS-cassette & Kumpfmüller et al. (2013) \\
\hline pJK64a & Reconstitution of genetic $s f p$ defect with lox-SSS-cassette & Zobel et al. (2015) \\
\hline pJK93 & Deletion of $s r f A$ operon with remaining $\mathrm{Kan}^{\mathrm{R}}$-cassette & Zobel et al. (2015) \\
\hline pJK94 & Deletion of $s r f A$ operon with remaining $\mathrm{Spec}^{\mathrm{R}}$-cassette & This study \\
\hline pJK111 & Deletion of $s r f A$ operon with SSS-cassette & This study \\
\hline pJK119 & Integration of ery $A I$ with acoA-promoter in $s r f A$ gene locus ( $\mathrm{Spec}^{\mathrm{R}}$-cassette) & This study \\
\hline $\mathrm{pJK} 119 \mathrm{c}$ & Integration of eryAI with acoA-promoter in $s r f A$ gene locus (lox-SSS-cassette) & This study \\
\hline pJK123 & Deletion of $\operatorname{srfA}$ operon with remaining $\mathrm{Kan}^{\mathrm{R}}$-cassette & Kumpfmüller, unpublished \\
\hline pJK126 & Deletion of $s r f A$ operon with remaining $\mathrm{Nm}^{\mathrm{R}}$-cassette & Kumpfmüller, unpublished \\
\hline pJK134 & Deletion of $s r f A$ operon with remaining $\mathrm{Kan}^{\mathrm{R}}$ and $\mathrm{Cm}^{\mathrm{R}}$ for RedET cloning & This study \\
\hline pJK139 & Integration of eryAII with acoA-promoter in $s r f A$ gene locus ( $\operatorname{Kan}^{\mathrm{R}}$-cassette) & This study \\
\hline pJK139a & Integration of eryAII with acoA-promoter in $s r f A$ gene locus ( $\operatorname{Kan}^{\mathrm{R}}$ - and lox-SSS-cassette) & This study \\
\hline pJK140 & Integration of eryAII with RBS in $s r f A$ gene locus ( $\operatorname{Kan}^{\mathrm{R}}$-cassette) & This study \\
\hline pJK140a & Integration of eryAII with RBS in srfA gene locus ( $\operatorname{Kan}^{\mathrm{R}}$ - and lox-SSS-cassette) & This study \\
\hline pJK155 & Integration of wild-type ery $A I-I I I$-cluster with $a c o A$-promoter in $s r f A$ gene locus & This study \\
\hline pJK179 & Deletion of $p k s X$ operon & Zobel et al. (2015) \\
\hline pJK191 & Deletion of $s r f A$ operon & Zobel et al. (2015) \\
\hline pJK205 & Insertion in $l y t C$ gene locus & Zobel et al. (2015) \\
\hline pJK206 & Deletion of $s r f A$ operon with $\mathrm{Kan}^{\mathrm{R}}$ - and lox-SSS-cassette & This study \\
\hline pJK209 & Deletion of spoIIGA gene & Zobel et al. (2015) \\
\hline pJK219 & $\begin{array}{l}\text { Toolbox-plasmid for integration of CDS with } a c o A \text {-promoter in } s r f A \text { gene locus (lox-SSS- } \\
\text { cassette) }\end{array}$ & This study \\
\hline pJK226 & Deletion of restriction and modification system & Zobel et al. (2015) \\
\hline $\mathrm{pJK} 245$ & Integration of eryAIII with $a c o A$-promoter in srfA gene locus & This study \\
\hline pJK246 & Integration of eryAIII with RBS in $s r f A$ gene locus & This study \\
\hline pJK254 & Deletion of pps operon & This study \\
\hline pJK257 & Integration of ery-orf5 with acoA-promoter in $\operatorname{srfA}$ gene locus & This study \\
\hline $\mathrm{pJK} 258$ & Integration of ery-orf5 with $a c o A$-promoter in $s r f A$ gene locus, in addition to ery $A I-I I I$-cluster & This study \\
\hline pJK260 & Deletion of prp operon & This study \\
\hline pMSE3 & High-copy E. coli/B. subtilis shuttle vector with $\mathrm{Kan}^{\mathrm{R}}$-cassette & Silbersack et al. (2006) \\
\hline
\end{tabular}

$\mathrm{Cm}^{R}$ chloramphenicol resistance cassette, $\operatorname{Kan}^{R}$ kanamycin resistance cassette, $\mathrm{Nm}^{R}$ neomycin resistance cassette, Spec $^{R}$ spectinomycin resistance cassette, ss six site, SSS Spec ${ }^{\mathrm{R}}$ flanked by two ss, lox-SSS SSS surrounded by a lox71 and lox66 site

${ }^{a}$ The cosmid P1394 was received from the cosmid library of the Peter Leadlay laboratory from the Department of Biochemistry at the University of Cambridge. The cosmid sequence with the eryAI-III-cluster can be found on the "Saccharopolyspora erythraea genome project web site" at http://131. 111.43.95/gnmweb/index.html.

\section{Construction of strains}

In this study, an optimized protocol for rapid and multiple genome modification of B. subtilis was used which was previously described (Kumpfmüller et al. 2013). For comS induction, $100 \mu \mathrm{M}$ isopropyl- $\beta$-D-thiogalactoside (IPTG) was added when the cells were diluted. Unless stated otherwise, the antibiotic selection marker was removed after successful chromosomal integration using a method based on the recombination of flanking lox sites with chromosomally localized cre as described in the above mentioned protocol. For B. subtilis, antibiotics were used in the following final concentrations: $100 \mu \mathrm{g} / \mathrm{mL}$ spectinomycin, $20 \mu \mathrm{g} / \mathrm{mL}$ kanamycin, and $20 \mu \mathrm{g} / \mathrm{mL}$ zeocin. 
Table 2 Strains used in this study

\begin{tabular}{|c|c|c|}
\hline Strain & Relevant genotype & Reference \\
\hline B. subtilis 168 & Wild type, sfp $^{0}$ & Zeigler et al. (2008) \\
\hline $\begin{array}{l}\text { B. subtilis } \\
\text { JK13 }\end{array}$ & $\Delta$ sacA::(Zeo ${ }^{R}, P_{\text {spac }}-\mathrm{comS}$, lacI, $\left.P_{x y l A^{-}}-\mathrm{cre}, x y l R\right)$ & Zobel et al. (2015) \\
\hline $\begin{array}{l}\text { B. subtilis } \\
\text { JK34 }\end{array}$ & BsJK13+ $\Delta$ srfA::comS, $\operatorname{Kan}^{R}$, lox72 & This study \\
\hline $\begin{array}{l}\text { B. subtilis } \\
\text { JK47 }\end{array}$ & BsJK34+RM::lox72 & This study \\
\hline $\begin{array}{l}\text { B. subtilis } \\
\text { JK53 }\end{array}$ & BsJK34+ $\Delta$ srfA $::\left(P_{\text {acoA }}\right.$-eryAI-T7, lox72) & This study \\
\hline $\begin{array}{l}\text { B. subtilis } \\
\text { JK54 }\end{array}$ & BsJK53+RM::lox72 & This study \\
\hline $\begin{array}{l}\text { B. subtilis } \\
\text { JK57 }\end{array}$ & BsJK47+ $\Delta s r f A::\left(P_{a c o A}-e r y A I-T 7, P_{a c o A}-e r y A I I, K_{a n}{ }^{R}\right.$, lox72) & This study \\
\hline $\begin{array}{l}\text { B. subtilis } \\
\text { JK58 }\end{array}$ & BsJK47+ $\Delta s r f A:\left(P_{a c o A^{-}}\right.$eryAI-T7, $P_{a c o A^{-}}$eryAII -T7, $P_{a c o A^{-}}$eryAIII-T7, lox72) & This study \\
\hline $\begin{array}{l}\text { B. subtilis } \\
\text { JK59 }\end{array}$ & BsJK58+sfp ${ }^{+}: \because \operatorname{lox} 72$ & This study \\
\hline $\begin{array}{l}\text { B. subtilis } \\
\text { JK59-1 }\end{array}$ & BsJK59+ $\Delta$ amyE::lox72 & This study \\
\hline $\begin{array}{l}\text { B. subtilis } \\
\text { JK60 }\end{array}$ & BSJK59-1 + $\Delta s r f A: \because\left(P_{a c o A}-\right.$ eryAI-T7, $P_{a c o A^{-}}$eryAII $-T 7, P_{a c o A^{-}}$eryAIII-T7, lox72, $P_{a c o A}$-ery-orf5-T7) & This study \\
\hline $\begin{array}{l}\text { B. subtilis } \\
\text { JK62 }\end{array}$ & $B s J K 60+\Delta l y t C: \because \operatorname{lox} 72$ & This study \\
\hline $\begin{array}{l}\text { B. subtilis } \\
\text { JK63 }\end{array}$ & BsJK62+ $\Delta$ spoIIGA::lox72 & This study \\
\hline $\begin{array}{l}\text { B. subtilis } \\
\text { JK64 }\end{array}$ & BsJK47+ $\Delta s r f A::\left(P_{a c o A}\right.$-eryAI-RBS-eryAII, Kan $^{R}$, lox72) & This study \\
\hline $\begin{array}{l}\text { B. subtilis } \\
\text { JK65 }\end{array}$ & BsJK47+ $\Delta s r f A::\left(P_{a c o A}\right.$-eryAI-RBS-eryAII-RBS-D3-T7, lox72) & This study \\
\hline $\begin{array}{l}\text { B. subtilis } \\
\text { JK66 }\end{array}$ & BsJK65+sfp ${ }^{+}: \because \operatorname{lox} 72$ & This study \\
\hline $\begin{array}{l}\text { B. subtilis } \\
\text { JK66-1 }\end{array}$ & BsJK66+ $\Delta$ amyE: :lox 72 & This study \\
\hline $\begin{array}{l}\text { B. subtilis } \\
\text { JK68 }\end{array}$ & BsJK63+ $\Delta p k s X:: \operatorname{lox} 72$ & This study \\
\hline $\begin{array}{l}\text { B. subtilis } \\
\text { JK70 }\end{array}$ & BsJK47+ $\Delta s r f A: \because\left(P_{\text {acoA }}\right.$-eryAI-III nat $T 7$, ss $)$ & This study \\
\hline $\begin{array}{l}\text { B. subtilis } \\
\text { JK71 }\end{array}$ & BsJK70+sfp ${ }^{+}: \because \operatorname{lox} 72$ & This study \\
\hline $\begin{array}{l}\text { B. subtilis } \\
\text { JK71-1 }\end{array}$ & BsJK71+ $\triangle$ amyE: :lox 72 & This study \\
\hline $\begin{array}{l}\text { B. subtilis } \\
\text { JK84 }\end{array}$ & 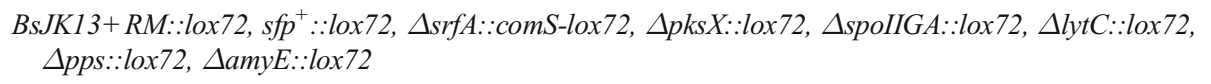 & $\begin{array}{l}\text { Kumpfmüller, } \\
\text { unpublished }\end{array}$ \\
\hline $\begin{array}{l}\text { B. subtilis } \\
\text { JK120 }\end{array}$ & BsJK68+ $\Delta$ pps::lox72 & This study \\
\hline $\begin{array}{l}\text { B. subtilis } \\
\text { JK125 }\end{array}$ & BsJK120+ Aprp::lox72 & This study \\
\hline
\end{tabular}

$\operatorname{Kan}^{R}$ kanamycin resistance cassette, $\operatorname{Spec}^{R}$ spectinomycin resistance cassette, $Z_{e 0}{ }^{R}$ zeocin resistance cassette, ss six site, lox 72 lox72 site

\section{Media and cultivation}

For expression studies, B. subtilis strains were cultivated in the fed-batch simulating EnBase ${ }^{\circledR}$ system from BioSilta. To this purpose, the EnPresso B Tablet Cultivation Set was used in combination with 24-well deepwell culture plates and airporous seals for multi-well plates (all BioSilta, Oulu,
Finland). For cultivation, $2 \mathrm{~mL}$ of prepared medium (including $0.1 \%$ acetoin for promoter induction, $1.5 \mathrm{U} / \mathrm{L}$ Reagent $\mathrm{A}$ for enzyme-based substrate delivery, $20 \mu \mathrm{g} / \mathrm{mL}$ zeocin for selection, and $20 \mathrm{mM}$ sodium propionate as $6 \mathrm{dEB}$ precursor, if not indicated otherwise) was inoculated with $100 \mu \mathrm{L}$ of a late-exponential pre-culture (LB medium; $37{ }^{\circ} \mathrm{C}, \mathrm{OD}_{600}$ approx. 2.0) and incubated at $30{ }^{\circ} \mathrm{C}$ at $250 \mathrm{rpm}(25-\mathrm{mm}$ 
Table 3 Transcriptional and translational elements of the native and the modified eryAI-III gene cassettes

\begin{tabular}{lllllll}
\hline Strain & mRNA & Gene & RBS & $\leftarrow$ Distance $\rightarrow$ & Start codon & Stop codon \\
\hline B. subtilis JK59-1 & \multirow{2}{*}{ monocistronic } & eryAI & GGAGGA & $7 \mathrm{bp}$ & ATG & TAA \\
& & eryAII & GGAGGA & $7 \mathrm{bp}$ & ATG & TAA \\
& & eryAIII & GGAGGA & $7 \mathrm{bp}$ & ATG & TAA \\
B. subtilis JK66-1 & \multirow{2}{*}{ tricistronic } & eryAI & GGAGGA & $7 \mathrm{bp}$ & ATG & TAA \\
& & eryAII & GGAGGA & $7 \mathrm{bp}$ & ATG & TAA \\
& & eryAIII & GGAGGA & $7 \mathrm{bp}$ & ATG & TAA \\
B. subtilis JK71-1 & \multirow{2}{*}{ tricistronic } & eryAI & GGAGGA & $7 \mathrm{bp}$ & ATG & TGA \\
& & eryAII & TGGAGA & $4 \mathrm{bp}$ & GTG & TAG \\
& & eryAIII & AGAGGA & $7 \mathrm{bp}$ & ATG & TAA \\
\hline
\end{tabular}

amplitude). After overnight culture (16 h), $200 \mu \mathrm{L}$ of the dissolved booster solution and another 1.5 U/L Reagent A were added and the cultivation was continued for $48 \mathrm{~h}$ under shaking conditions.

\section{RNA isolation and analysis}

RNA isolation was done as previously described (Welsch et al. 2012). For slot blot analyses, the Bio-Dot SF Microfiltration Apparatus (Bio-Rad, Munich, Germany) was used according to the manufacturer's protocol. RNA probes were prepared using the DIG RNA Labeling Kit (SP6/T7) from Roche Life Science (Mannheim, Germany) and the following primers: eryAI, 5056/5490; eryAII, 5105/5496; and eryAIII, 5492/5493. Hybridization and detection were performed as described elsewhere (Welsch et al. 2012).

\section{Extraction}

After cultivation, the cells were harvested and $1300 \mu \mathrm{L}$ of the supernatant was supplemented with $13 \mu \mathrm{L}$ of internal standard mixture ( $1 \mathrm{ng} / \mu \mathrm{L}$ sulfadimethoxine, $2 \mathrm{ng} / \mu \mathrm{L}$ sulfachloropyridazine in methanol, HPLC grade). Subsequently, samples were extracted with an equal volume of ethyl acetate and agitated for $10 \mathrm{~min}$ at $30^{\circ} \mathrm{C}$. Phase separation was performed via centrifugation at room temperature and $8500 \mathrm{rpm}$ for $5 \mathrm{~min}$. After ethyl acetate was evaporated under vacuum, the extracts were dissolved in $75 \mu \mathrm{L}$ HPLC-grade methanol for HPLC-mass spectrometry (MS) analysis.

\section{HPLC and mass spectrometry}

All experiments were carried out on an Agilent 1200 HPLC system coupled to a 6460 Triple Quadrupole mass spectrometer equipped with a Jet stream ESI-source (Agilent Technologies, Waldbronn, Germany). The chromatographic separation was achieved temperature controlled at $25{ }^{\circ} \mathrm{C}$ on a Synergi Fusion-RP column $(2.5 \mu \mathrm{m}, 50 \times 2.0 \mathrm{~mm})$ equipped with a pre-column of the same material $(4 \times 2.0 \mathrm{~mm})$ both from
Phenomenex (Aschaffenburg, Germany). A gradient of mobile phase A ( $0.1 \%$ formic acid) and mobile phase B (acetonitrile) was used as shown in Table S2 in the Supplementary Material (flow rate of $0.5 \mathrm{~mL} / \mathrm{min}$, injection volume of $10 \mu \mathrm{L}$ ). The MS was operated in positive ion mode with multi-reaction monitoring (MRM). The MS/MS fragmentation pattern of $6 \mathrm{dEB}$ and the internal standard compounds were determined and the MS parameters were optimized. The optimized source parameters are displayed in Table S3 in the Supplementary Material.

6dEB was monitored with transitions $\mathrm{m} / \mathrm{z} 409.1$ to $\mathrm{m} / \mathrm{z}$ 311.2 for relative quantification and $\mathrm{m} / \mathrm{z} 409.1$ to $\mathrm{m} / \mathrm{z} 391.2$ and $\mathrm{m} / \mathrm{z} 293.2$ for identification. Collision energies for the transitions of $6 \mathrm{dEB}$ were 25,21 , and $25 \mathrm{~V}$, respectively. Data was acquired and evaluated using the Mass Hunter software; quantitative analysis was done using Mass Hunter Quantitative Analysis (version B03.02, Agilent Technologies, Waldbronn, Germany).

\section{6dEB quantification}

For quantification of 6dEB titers, the culture volume was increased to $100 \mathrm{~mL}$, and 500-mL Ultra Yield Flasks with the according AirOTop Seals (BioSilta, Oulu, Finland) were used. Supplementation, induction, inoculation, and cultivation were performed as mentioned above. Metabolites form these cultures were extracted twice with $100 \mathrm{~mL}$ ethyl acetate and dried with sodium sulfate afterward. After evaporation of the solvent, the extracts were quantified as described elsewhere (Zhang et al. 2015).

\section{Results}

\section{Construction of the DEBS expression strains}

All plasmids for integration of the eryAI-III genes are presented in Fig. S2 in the Supplementary Material. The construction of these plasmids is explained in the Supplementary Material 
text and by Fig. S3 in the Supplementary Material. The starting strain used in this study was B. subtilis JK13 (Zobel et al. 2015), a derivative of the Marburg 168 strain, which already contained an IPTG-inducible second gene copy of the competence factor ComS for enhanced transformation efficiency and the xylose-inducible cre gene for marker removal.

In order to investigate the expression of the eryI-III gene cluster from Saccharopolyspora erythraea, which comprises more than $30 \mathrm{~kb}$, in $B$. subtilis, the DEBS genes were localized to the $B$. subtilis JK13 chromosome in three different cluster organizations: (A) native operon, (B) native operon with optimized ribosomal binding sites, and (C) the three native ery gene sequences as separate cassettes with optimized ribosomal binding sites. The operons and the individual gene cassettes were set under control of the acetoin inducible aco $A$ promoter.

Due to a frame shift mutation in the PPTase $s f p$ gene, B. subtilis 168 strains are not able to activate NRPS and PKS enzymes (Mootz et al. 2001). Hence, they do not produce hemolytic surfactin and deletion of the corresponding srfA operon cannot be detected on sheep blood agar plates. In order to allow simple screening for positive transformants after chromosomal integration of the eryAI-III genes in the srfA gene locus, first a $\mathrm{Kan}^{\mathrm{R}}$-cassette was inserted by chromosomal integration of pJK206 in B. subtilis JK13. The resulting strain $B$. subtilis JK34 was then treated with linearized pJK119c to chromosomally integrate the $P_{\text {acoA }}$-eryAI$\mathrm{T}_{\mathrm{T} 7}$-operon thereby replacing the $\mathrm{Kan}^{\mathrm{R}}$ gene. Thus, the obtained eryI-positive colonies could be screened for loss of kanamycin resistance. For further integration of the eryAII gene, the restriction and modification (RM) system (namely, $y d z T-W, y d i P-S$, and $y d j A-C$ ) of the resulting strain (B. subtilis JK53) had to be deleted by chromosomal integration of pJK226 to give $B$. subtilis JK54. The positive effect of this knockout (higher transformation efficiency with large DNA fragments) was already described elsewhere (Choi et al. 2009; Haima et al. 1987). Hereafter, B. subtilis JK54 was transformed with plasmid pJK139a, resulting in B. subtilis JK57. Thereby, a $\mathrm{Kan}^{\mathrm{R}}$-cassette was introduced together with the $P_{\text {acoA }}$-eryAII-operon allowing screening for another resistance switch after the following chromosomal integration of the $P_{\text {acoA-eryAIII- }} \mathrm{T}_{\mathrm{T} 7}$-operon by using pJK245. Hence, the resulting strain B. subtilis JK58 harbored all three eryA genes as distinct cassettes, each under the control of the acoA promoter (Ali et al. 2001). In a final step, $s f p$ activity was reconstituted by chromosomal integration of $\mathrm{pJK} 64 \mathrm{a}$, giving $B$. subtilis JK59. The stepwise construction of this strain is shown in Fig. 1.
For chromosomal integration of the modified eryAI-III operon with optimized ribosomal binding sites, $B$. subtilis JK54 was used (see also Fig. 1). The RBS-eryAII-cassette was chromosomally introduced together with a $\mathrm{Kan}^{\mathrm{R}}$-cassette by using pJK140a and thereby removing the T7-terminator of the $P$ acoA-eryAI- $\mathrm{T}_{\mathrm{T} 7}$-operon resulting in B. subtilis JK64. Hereafter, pJK246 was used for chromosomal integration of the eryAIII gene with optimized RBS to complete the $P_{a c o A}$-eryAI-RBSeryAII-RBS-eryAIII- $\mathrm{T}_{\mathrm{T} 7}$-operon. Due to the subsequent deletion of the $\mathrm{Kan}^{\mathrm{R}}$-cassette the obtained colonies could be screened for antibiotic resistance switch. For reconstitution of the required $s f p$ gene, this strain (B. subtilis JK65) was then transformed with pJK64a to give B. subtilis JK66 (Fig. S4 in the Supplementary Material).

A chromosomal integration of the 30-kb large wild-type eryAI-III-cluster could be done in a single step only after deletion of the RM system. Thus, pJK226 was used to transform $B$. subtilis JK34 to give the kanamycin-resistant B. subtilis JK47 strain. Hereafter, this mutant strain was treated with pJK155 thereby replacing the $\mathrm{Kan}^{\mathrm{R}}$-cassette. Positive clones could be screened for the selection marker switch. For subsequent marker removal, recombination of the flanking six-sites with a plasmid-coded $\beta$-recombinase was performed as described elsewhere (Kabisch et al. 2012) resulting in B. subtilis JK70, which carries the $P_{\text {acoA }}$-eryAI-III nat $-\mathrm{T}_{\mathrm{T} 7}$-operon. Again, this strain was then transformed with pJK64a for $s f p$ reconstitution giving $B$. subtilis JK71 (Fig. S5 in the Supplementary Material).

Since the fed-batch simulating EnBase ${ }^{\circledR}$ system, which was used for expression studies, is based on the enzymatic release of glucose from a polymer, the $a m y E$ gene coding for the $\alpha$-amylase had to be knocked out to avoid interference with the tightly controlled substrate delivery by an artificially added amylase. For this purpose, pAMY-lox-SSS was used to chromosomally delete the amyE locus of B. subtilis JK59, JK66, and JK71 to give the amylase-negative strains $B$. subtilis JK59-1, JK66-1, and JK71-1, respectively.

\section{Cultivation of DEBS expression strains and detection of $6 \mathrm{dEB}$ production}

All three expression strains were cultivated under fed-batch simulating conditions and showed a similar growth behavior that differed from the negative control beginning from $t=40 \mathrm{~h}$ ( $24 \mathrm{~h}$ post-boostering, see Fig. 2a). This observed reduced cell growth could be a hint for the induced gene expression in these recombinant strains. To qualify specific messenger RNA (mRNA) production, RNA isolation followed by a slot blot analysis was performed. The results indicated that the eryAI-III genes were transcribed in all three $B$. subtilis strains independent of the cluster organization (Fig. S6 in the Supplementary Material). However, significant $6 \mathrm{dEB}$ production could only be detected for BsJK59-1 which harbored the 
A B. subtilis JK34

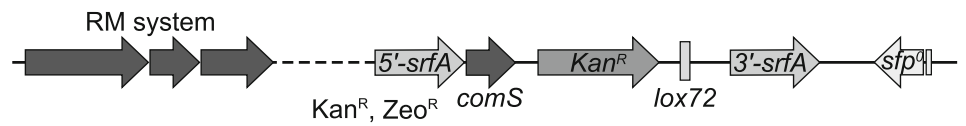

$\downarrow$ pJK119c

$\mathrm{Spec}^{R}, \mathrm{ZeO}^{\mathrm{R}}$

$\downarrow$ Recombination of lox sites

B B. subtilis JK53

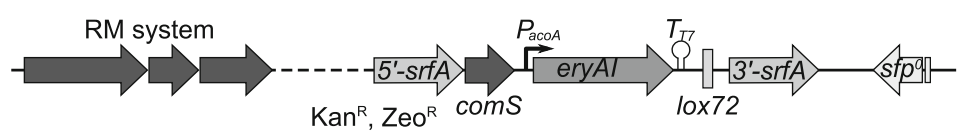

$\downarrow$ pJK226

$\operatorname{Spec}^{R}, Z^{2} o^{R}$

$\downarrow$ Recombination of lox sites

C B. subtilis JK54

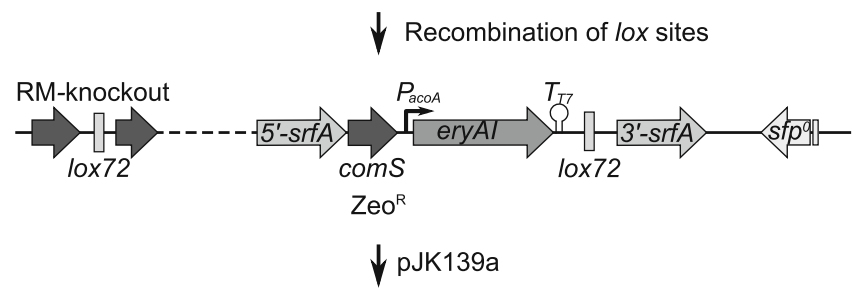

$\mathrm{Kan}^{\mathrm{R}}, \mathrm{Spec}^{\mathrm{R}}, \mathrm{Zeo}^{\mathrm{R}}$

D B. subtilis $J K 57$

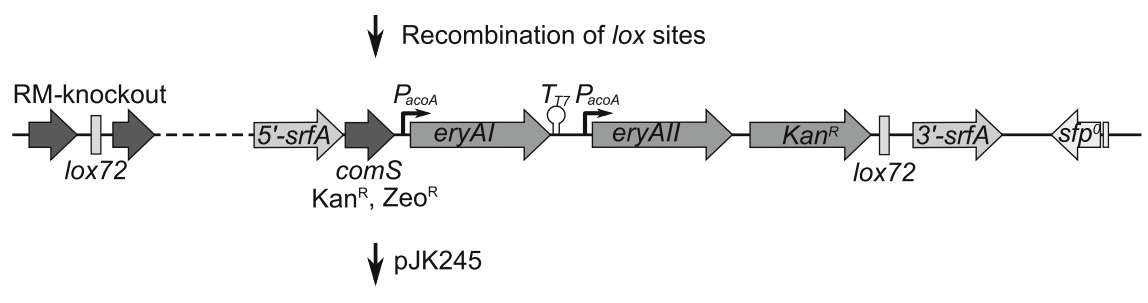

$\operatorname{Spec}^{\mathrm{R}}, \mathrm{Zeo}^{\mathrm{R}}$

$\downarrow$ Recombination of lox sites

E B. subtilis JK58

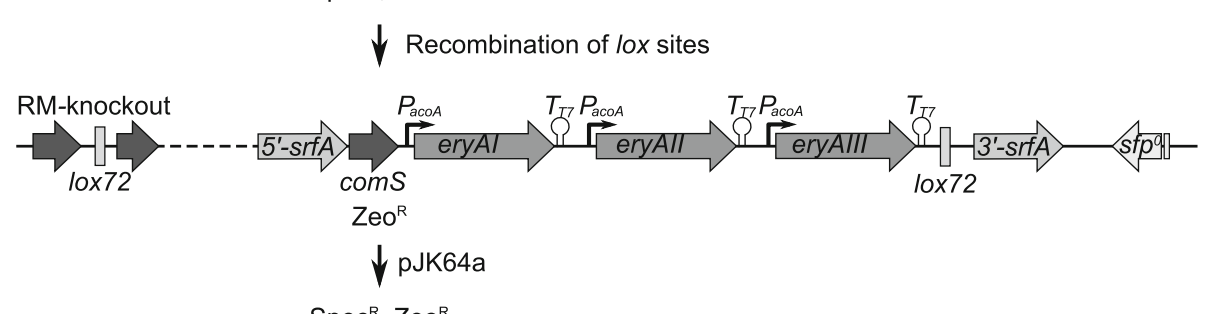

$\operatorname{Spec}^{R}, Z^{2} o^{R}$

$\downarrow$ Recombination of lox sites

F $\quad$ B. subtilis JK59

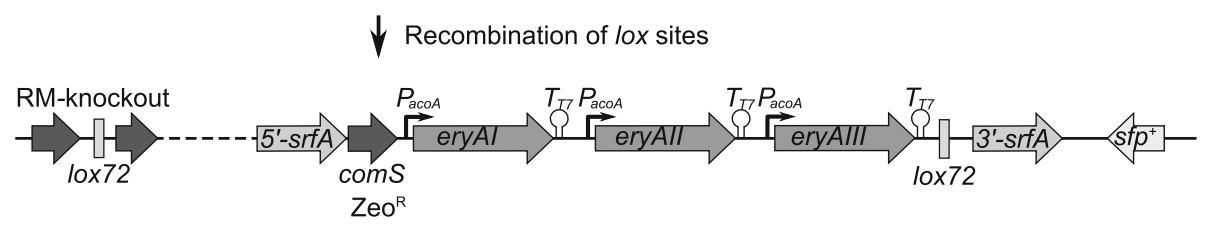

Fig. 1 Integration of eryAI, eryAII, and eryAIII as three individually controlled genes with optimized RBS in B. subtilis JK34. Schematic diagram (not to scale) showing the construction of B. subtilis JK59. a The former srfA gene locus in the chromosome of B. subtilis JK34. Transformation of this strain with $\mathrm{pJK} 119 \mathrm{c}$ and subsequent recombination of the lox sites via Cre resulted in B. subtilis JK53 (b). Deletion of the RM system via pJK226 resulted in B. subtilis JK54 (c). Stepwise chromosomal

integration of the eryAII and eryAIII genes under control of the aco $A$ promoter via pJK139a and pJK245 resulted in B. subtilis JK57 (d) and B. subtilis JK58 (e), respectively. In a final step, the frame shift mutated $s f p^{0}$ gene was chromosomally replaced by the native $s f p^{+}$gene by using pJK64a to give B. subtilis JK59 (f). Thus, PPTase activity of Sfp was reconstituted

DEBS genes in three separate cassettes (Fig. 2b). For this strain, it could also be revealed that relative $6 \mathrm{dEB}$ yield was more than doubled by prolongation of the EnBase-based cultivation to $48 \mathrm{~h}$ after boostering (data not shown).

Furthermore, it could be shown that the metabolite is completely secreted, because no 6dEB could be detected in an extract obtained from the cell pellet treated by sonification (data not shown). 

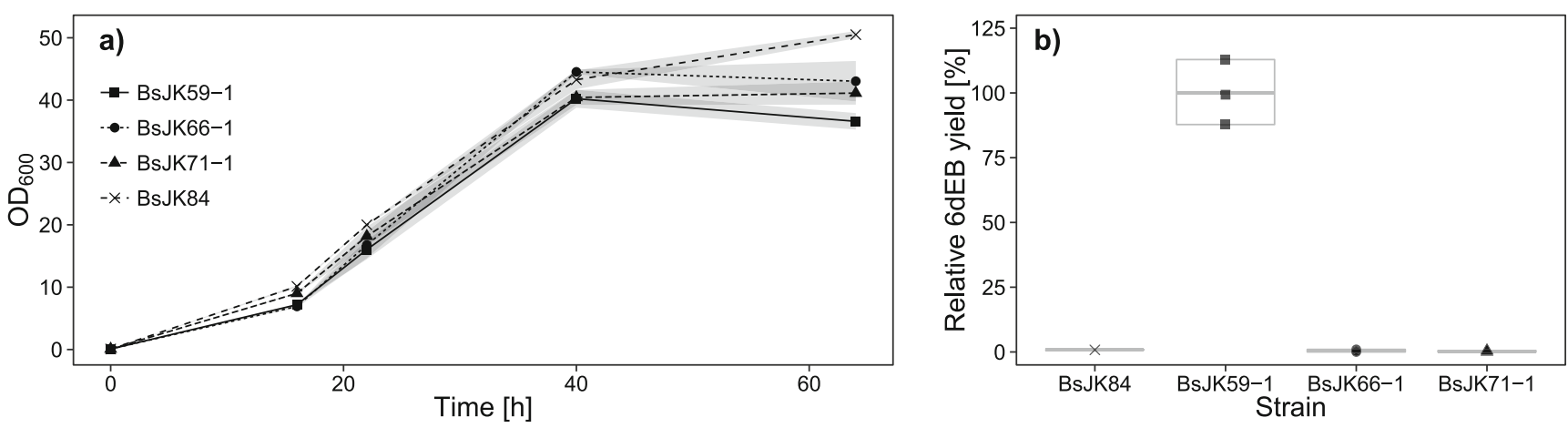

Fig. 2 Comparison of engineered B. subtilis strains carrying the DEBS genes in different cluster organizations. a Growth curves $\left(\mathrm{OD}_{600}\right)$ during cultivation for $64 \mathrm{~h}\left(16 \mathrm{~h}\right.$ pre- plus $48 \mathrm{~h}$ post-boostering) in EnBase ${ }^{\mathbb{R}}$ medium. b Quantitative MRM analysis of secreted 6dEB of modified

\section{Optimization of 6dEB production in B. subtilis BsJK59-1 by engineering the genetic background}

For potential optimization of $6 \mathrm{dEB}$ production, further genome modifications were investigated. First, the DEBS-specific type II thioesterase (TEII) encoded by the ery-orf5 gene was chromosomally integrated in $B$. subtilis JK59-1 by using pJK258 to give $B$. subtilis JK60. This accessory enzyme is known to increase 6dEB production in the native producer as well as in the surrogate E. coli host (Pfeifer et al. 2002). For enhanced cell growth during heterologous protein production, this strain was then transformed with $\mathrm{pJK} 205$ to generate a $l y t C$ knockout mutant B. subtilis JK62 (Kabisch et al. 2012). Hereafter, spoIIGA (involved in sporulation) was deleted by chromosomal integration of pJK209 to give the sporulation-deficient strain B. subtilis JK63. In order to reduce the metabolic burden of the host, two gene clusters involved in secondary metabolite production were removed from the chromosome in addition to the $\operatorname{srfAA} A-D$ operon. To this purpose, the pks $A-R$ operon $(\sim 76 \mathrm{~kb})$ was deleted by using pJK179 resulting in $B$. subtilis JK68, which was not able to produce the polyketide bacillaene. In a next step, this strain was transformed with pJK254 to give $B$. subtilis JK120 with a deletion of the $38 \mathrm{~kb}$ pps $A-E$ cluster, coding for the plipastatin synthetase (NRPS).

The highest growth rate could be detected for B. subtilis JK62 (DEBS1-3, TEII, $\Delta l y t C$ ), followed by $B$. subtilis JK60 (DEBS1-3, TEII). B. subtilis JK63 (DEBS1-3, TEII, $\Delta l y t C$, $\Delta$ spoIIGA) and JK68 (DEBS1-3, TEII, $\triangle l y t C, \Delta$ spoIIGA, $\Delta p k s X)$ both resulted in a similar cell density compared to the control strain JK62. It is interesting to note that the unmodified 6dEB producer $B$. subtilis JK59-1 and the $B$. subtilis JK120 strain, showing all mentioned modifications, revealed the lowest maximal optical densities (see Fig. 3a).

According to the productivity, the relative $6 \mathrm{dEB}$ yield was reduced from $100 \%$ in B. subtilis JK59-1 to $69 \%$ in B. subtilis JK60 by introduction of the TEII. The additional deletion of $l y t C$ resulted in the compensation of this negative effect, whereby B. subtilis JK62 reached a similar relative 6dEB
B. subtilis strains ( $t=48 \mathrm{~h}$ after boostering). BsJK59-1: three individually controlled genes; BsJK66-1: one operon with modified RBS; BsJK71-1: wild-type operon; BsJK84: negative control. $N=3$, therefore no quartiles, but the median is shown

yield. The spoIIGA knockout in B. subtilis JK63 resulted in a further enhanced productivity (132\%), which was not affected by the additional deletion of the $p k s A-R$ operon in B. subtilis JK68 (129\%). Best results could be obtained with B. subtilis JK120 that also showed the deletion of the ppsA-E operon and yielded $143 \%$ (Fig. 3b).

\section{Influence of the modification of the propionyl-CoA metabolism}

To optimize the propionyl-CoA metabolism with regard to the $6 \mathrm{dEB}$ production, the prpBD operon in B. subtilis JK120 responsible for propionyl-CoA utilization was deleted by using pJK260, resulting in B. subtilis JK125. In addition to this modification, the removal of propionate, which had always been provided as supplementation, was also investigated.

In general, the cell growth was slightly increased during the cultivation without propionate. Furthermore, the B. subtilis JK125 strain reached higher cell densities compared to B. subtilis JK120 (Fig. 4a).

Supplementing the medium with $20 \mathrm{mM}$ sodium propionate resulted in an increase in the relative $6 \mathrm{dEB}$ yield of $20 \%$ for B. subtilis JK120 and $75 \%$ in case of the prpBD mutant strain B. subtilis JK125. In addition, in the presence of propionate, the relative 6dEB yield in B. subtilis JK125 was increased 2.5-fold compared to that in $B$. subtilis JK120. In contrast, the deletion of the $\operatorname{prp} B D$ operon resulted in a reduced $6 \mathrm{dEB}$ productivity $(-30 \%)$ in the unsupplemented medium (Fig. $4 b)$.

B. subtilis JK125, which has emerged as the best producer, was chosen to quantify the level of $6 \mathrm{dEB}$ production. Without further optimization of the culture conditions, a final $6 \mathrm{dEB}$ concentration of $2.6 \pm 0.3 \mu \mathrm{g} / \mathrm{L}$ was reached with this strain.

\section{Discussion}

Although the DEBS genes could be localized in the chromosome of $B$. subtilis in three different cluster organizations (A, 


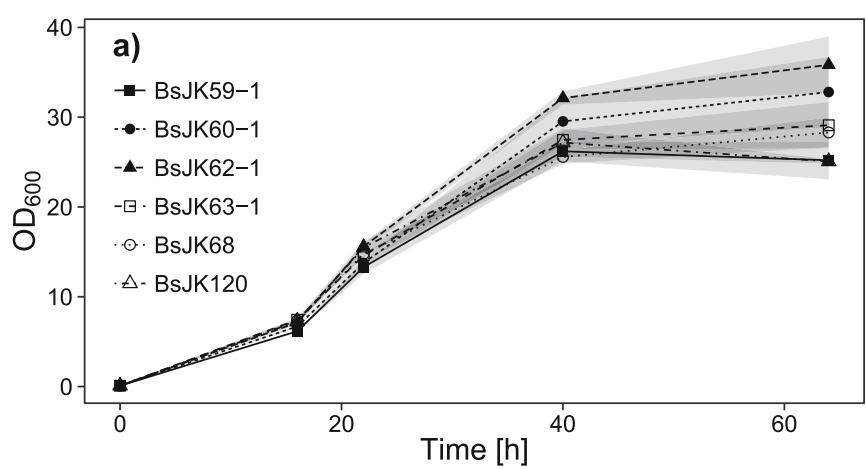

Fig. 3 Comparison of modified B. subtilis JK59-1 strains with engineered genetic background. a Growth curves $\left(\mathrm{OD}_{600}\right)$ during cultivation for $64 \mathrm{~h}$ (16 h pre- plus $48 \mathrm{~h}$ post-boostering) in EnBase ${ }^{\circledR}$ medium. b Quantitative MRM analysis of secreted $6 \mathrm{dEB}$ of modified $B$. subtilis strains $(t=48 \mathrm{~h}$ after boostering). BsJK59-1: three individually controlled genes with optimized

native operon; $\mathrm{B}$, modified native operon with optimized RBS; and C, three separately transcribed genes with optimized RBS) and specific mRNAs of eryAI, eryAII, and eryAIII could be identified in all three expression strains, heterologous $6 \mathrm{dEB}$ production could only be detected in the strain $B$. subtilis JK59-1, which controls the expression of the eryI-III genes by three separate $a c o A$ promoters and optimized ribosomal binding sites. The ery mRNA analyses indicate that not the transcription but the translation of the mRNAs is the critical step in the heterologous expression of the $6 \mathrm{dEB}$ gene clusters. It can be assumed that the monocistronic organization of the eryAI, eryAII, and eryAIII genes in JK59-1 is the main reason for the positive $6 \mathrm{dEB}$ synthesis as this is the only distinction to B. subtilis JK66-1, which exhibits a tricistronic mRNA and no detectable $6 \mathrm{dEB}$ titers. It could be speculated that a greater instability or unfavorable secondary structures of the $30-\mathrm{kb}$ tricistronic mRNA in contrast to the $10-\mathrm{kb}$ monocistronic mRNAs result in insufficient translational initiation and/or unbalanced expression levels of DEBS1, DEBS2, and DEBS3.

It is also demonstrated that only a fed-batch cultivation strategy with the chosen $a c o A$ promoter system resulted in a significant $6 \mathrm{dEB}$ biosynthesis. On the one hand, this might be an effect of the higher cell densities that could be reached in

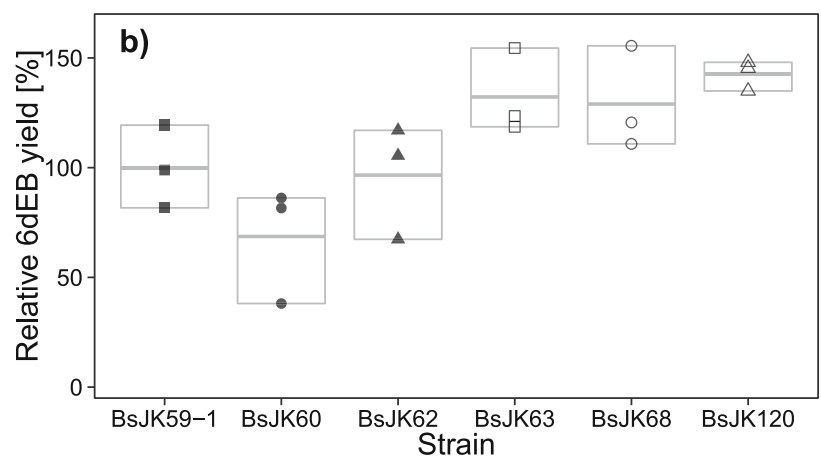

RBSs; BsJK60: additional expression of ery orf5 (TE II); BsJK62: with lytC inactivation; BsJK63: with spoIIGA inactivation; BsJK68: deletion of bacillaene synthase cluster; BsJK120: deletion of plipastatin synthase cluster. $N=3$, therefore no quartiles, but the median is shown

the fed-batch simulating EnBase medium. However, it is more likely that it is a result of the linear cell growth that does not cause oxygen limitation, overflow metabolism, and $\mathrm{pH}$ drop (Panula-Perälä et al. 2008). This, in turn, leads to higher protein expression in combination with enhanced metabolic activity (Ukkonen et al. 2011). Thus, a higher synthesis rate of the metabolite can be achieved. This could, for example, already be demonstrated by the increased heterologous production of valinomycin in $E$. coli ( $\mathrm{Li}$ et al. 2014).

Furthermore, when using B. subtilis JK59-1, it could be shown that the $6 \mathrm{dEB}$ metabolite accumulates during the last $24 \mathrm{~h}$ of cultivation. The productivity of the heterologous host even rose since $6 \mathrm{dEB}$ titers could be more than doubled during that time with consistent cell density. This indicates that the metabolite synthesis is not limited by the depletion of one of the substrates and that the DEBS proteins are expressed at a constant level.

In addition, 6dEB was exclusively detectable in the medium but not in the cell extract. Thus, the metabolite seems to be completely secreted into the supernatant. It is noteworthy that such a secretory production is advantageous, especially for simplified detection and downstream processing.
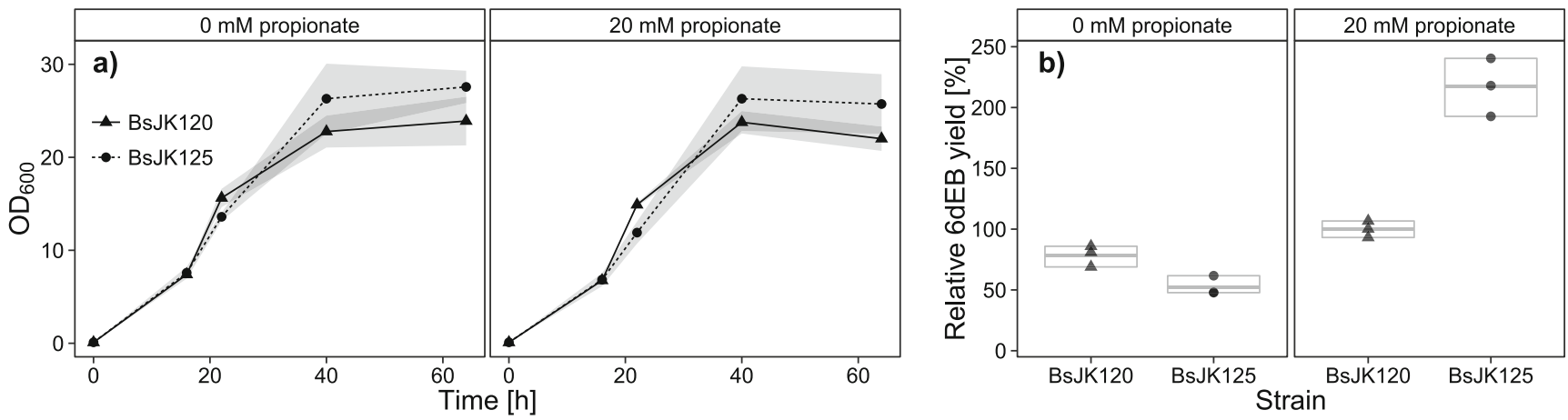

Fig. 4 Influence of the prpBD knockout and feeding of sodium propionate. a Growth curves $\left(\mathrm{OD}_{600}\right)$ during cultivation for $64 \mathrm{~h}(16 \mathrm{~h}$ pre- plus $48 \mathrm{~h}$ post-boostering) in EnBase ${ }^{\circledR}$ medium. b Quantitative

MRM analysis of secreted 6dEB of modified B. subtilis strains $(t=48 \mathrm{~h}$ after boostering). BsJK120: prpBD positive control; BsJK125: deletion of $\operatorname{prp} B D$ operon. $N=3$, therefore no quartiles, but the median is shown 
To enhance 6dEB synthesis, the DEBS-specific TEII encoded by ery-orf5 was chromosomally integrated in B. subtilis JK59-1. In general, the function of these discrete hydrolytic enzymes, which are quite often associated with PKS and NRPS gene clusters, is to remove aberrant residues blocking the megasynthase, to participate in substrate selection as well as to release intermediates and products (Kotowska and Pawlik 2014). In recent studies, it could be shown that the deletion of the DEBS-TEII gene in the native host Saccharopolyspora erythraea led to both an increase of the side product 8, $8^{\prime}$-deoxyoleandolide (15-nor-6deoxyerythronolide $\mathrm{B}$ ) and lower erythromycin production (Hu et al. 2003). Furthermore, coexpression of this TEII in a 6 dEB producing $E$. coli strain resulted in a doubled product yield (Pfeifer et al. 2002). However, in contrast to our expectations, B. subtilis JK60, which harbored the ery-orf5 gene under the control of the acoA-promoter, showed a reduced 6dEB synthesis $(-30 \%)$ compared with the parental strain B. subtilis JK59-1. The background of this negative effect is not clear, and further investigations are necessary to gain better insight into this unexpected outcome.

Corresponding to the optimization of B. subtilis ATCC 6051 as an expression host (Kabisch et al. 2012), lytC (the major autolysin) as well as spoIIGA (involved in sporulation) was deleted to improve the growth behavior. As expected, the lyt $C$ knockout mutant $B$. subtilis JK62 showed a higher cell density compared to the parental strain $B$. subtilis JK60 and resulted in an enhanced $6 \mathrm{dEB}$ production $(+30 \%)$. Production levels could be further increased by the additional deletion of spoIIGA, although this knockout led to a reduced cell growth. The enhancement of the $6 \mathrm{dEB}$ synthesis $(+30 \%)$ in B. subtilis JK63 could be an unspecific effect of optimized cell metabolic processes due to the prevention of spore formation (Kabisch et al. 2012).

In addition to these growth-related modifications, the deletion of host-own PKS and NRPS gene clusters was performed in order to reduce the metabolic burden and potential cross talk. The $\operatorname{srf} A A-D$ genes $(\sim 26 \mathrm{~kb})$ responsible for surfactin production (NRP) were already removed by the chromosomal integration of the DEBS operon. Thus, the influence of this knockout on $6 \mathrm{dEB}$ production cannot be assessed. Contrary to our expectations, the deletion of the bacillaene synthase cluster (pksA-R, $76 \mathrm{~kb})$ in B. subtilis JK68 did not enhance the product yield compared to its parental strain JK63. This might be due to different substrates, which are necessary for $6 \mathrm{dEB}$ (propionyl- and methylmalonyl-CoA) and bacillaene (mainly malonyl-CoA) synthesis, whereby no direct competition for starter and extender units exists. The $p p s A-E$ knockout mutant B. subtilis JK120 also showed no significant increase in 6dEB formation compared to the JK68 control strain. Although the removal of genes of the secondary metabolism did not enhance cell growth and has only a weak effect on $6 \mathrm{dEB}$ synthesis, these deletions might be of particular interest for an industrial production strain. Due to safety reasons and simplification of the downstream process, "clean" hosts which do not produce unwanted side products are preferred.

As already mentioned, propionyl- and (2S)methylmalonyl-CoA are necessary for $6 \mathrm{dEB}$ synthesis. B. subtilis is capable of propionyl-CoA synthesis either from the isoleucine and valine degradation pathway or directly from propionate (Fig. 5). The starter unit propionyl-CoA can be either metabolized to succinate (via PrpB and PrpD) or converted to (2S)-methylmalonyl-CoA. Our data indicate that B. subtilis provides a significant propionyl- and methylmalonyl-CoA pool, but the native precursor concentration is not sufficient for an optimal 6dEB production. Thus, propionate feeding was not mandatory but conductive, and the positive effect of this supplementation could be enhanced by the deletion of the propionyl-CoA degradation pathway. Both procedures resulted in a better propionyl-CoA availability which in turn led to higher intracellular (2S)-methylmalonylCoA levels and thus to a more efficient 6dEB biosynthesis.

On the one hand, DEBS is one of the best investigated PKS systems (Khosla et al. 2007). Since the substrates, the structure of the enzymatic complex, and the mechanism of the
Fig. 5 Metabolic pathways of B. subtilis: connecting the propionate metabolism to heterologous $6 \mathrm{dEB}$ production. The map has been constructed from the KEGG Pathway Database [http://www.genome.jp/ kegg/pathway.html\#metabolism]

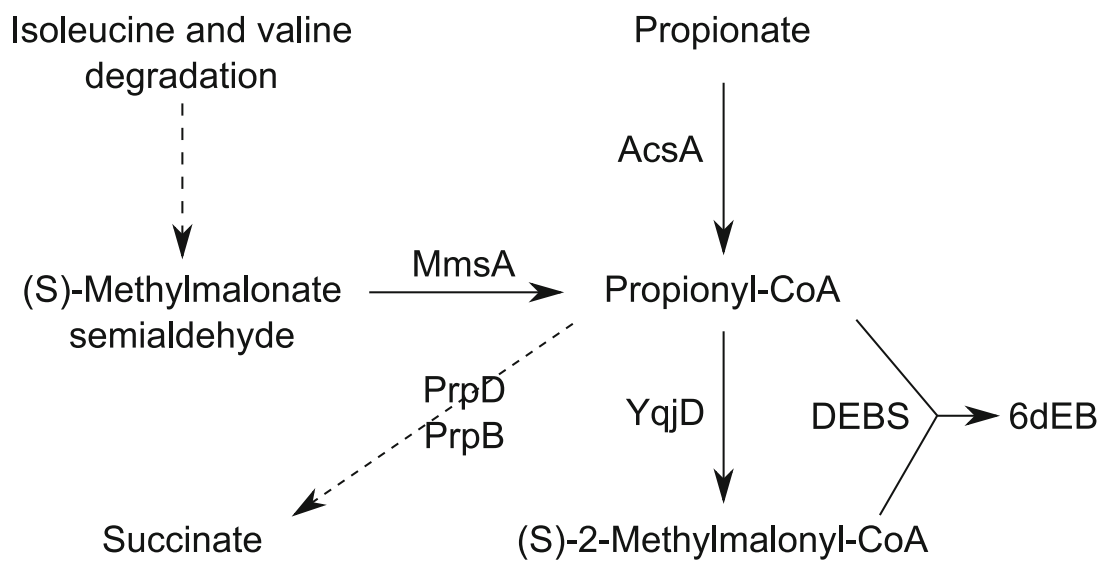


biosynthesis of $6 \mathrm{dEB}$ are known, it is a suitable candidate for a reference system. On the other hand, due to its complexity ( 28 active sites distributed among three linked proteins) and the size of the corresponding gene cluster $(\sim 30 \mathrm{~kb})$, cloning and heterologous expression are challenging. Nevertheless, it is demonstrated that $B$. subtilis is able to functionally express the eryAI-III genes, when the three DEBS genes with optimized RBS were individually expressed by separate promoters under fed-batch cultivation conditions. Although the final $6 \mathrm{dEB}$ production titer is not comparable with those reached by optimized E. coli strains (Zhang et al. 2010), this study indicates that $B$. subtilis is a suitable host for the secretory production of a complex polyketide. To our knowledge, this is the first communication for the heterologous production of a polyketide in the Gram-positive bacterium B. subtilis.

Acknowledgments The work of JK and TS was financially supported by the Ministry of Economy, Labour and Tourism of Mecklenburg Vorpommern and the European Fund for Regional Development (grant numbers V-630-S-177-2013/213 and V-630-F-177-2013/212).

Conflict of interest The authors declare that they have no conflict of interest.

Ethical approval This article does not contain any studies with human participants or animals performed by any of the authors.

Open Access This article is distributed under the terms of the Creative Commons Attribution 4.0 International License (http:// creativecommons.org/licenses/by/4.0/), which permits unrestricted use, distribution, and reproduction in any medium, provided you give appropriate credit to the original author(s) and the source, provide a link to the Creative Commons license, and indicate if changes were made.

\section{References}

Ali NO, Bignon J, Rapoport G, Debarbouille M (2001) Regulation of the acetoin catabolic pathway is controlled by sigma L in Bacillus subtilis. J Bacteriol 183:2497-2504. doi:10.1128/JB.183.8.24972504.2001

Arima K, Kakinuma A, Tamura G (1968) Surfactin, a crystalline peptidelipid surfactant produced by Bacillus subtilis: isolation, characterization and its inhibition of fibrin clot formation. Biochem Biophys Res Commun 31:488-494. doi:10.1016/0006-291X(68) 90503-2

Butcher RA, Schroeder FC, Fischbach MA, Straight PD, Kolter R, Walsh CT, Clardy J (2007) The identification of bacillaene, the product of the PksX megacomplex in Bacillus subtilis. Proc Natl Acad Sci 104: 1506-1509. doi:10.1073/pnas.0610503104

Cane DE, Walsh CT (1999) The parallel and convergent universes of polyketide synthases and nonribosomal peptide synthetases. Chem Biol 6:R319-R325. doi:10.1016/S1074-5521(00)80001-0

Choi SK, Park SY, Kim R, Kim SB, Lee CH, Kim JF, Park SH (2009) Identification of a polymyxin synthetase gene cluster of Paenibacillus polymyxa and heterologous expression of the gene in Bacillus subtilis. J Bacteriol 191:3350-3358. doi:10.1128/JB. 01728-08
Corcoran JW (1981) Biochemical mechanisms in the biosynthesis of the erythromycins. In: Corcoran JK (ed) Antibiotics, vol 4, Springer. New York, NY, pp 132-174

Eppelmann K, Doekel S, Marahiel MA (2001) Engineered biosynthesis of the peptide antibiotic bacitracin in the surrogate host Bacillus subtilis. J Biol Chem 276:34824-34831. doi:10.1074/jbc. M104456200

Haima P, Bron S, Venema G (1987) The effect of restriction on shotgun cloning and plasmid stability in Bacillus subtilis Marburg. Mol Gen Genet 209:335-342. doi:10.1007/BF00329663

$\mathrm{Hu}$ Z, Pfeifer BA, Chao E, Murli S, Kealey J, Carney JR, Ashley G, Khosla C, Hutchinson CR (2003) A specific role of the Saccharopolyspora erythraea thioesterase II gene in the function of modular polyketide synthases. Microbiol 149:2213-2225. doi: 10.1099/mic.0.26015-0

Kabisch J, Thürmer A, Hübel T, Popper L, Daniel R, Schweder T (2012) Characterization and optimization of Bacillus subtilis ATCC 6051 as an expression host. J Biotechnol 163:97-104. doi:10.1016/j.jbiotec. 2012.06.034

Kao CM, Katz L, Khosla C (1994) Engineered biosynthesis of a complete macrolactone in a heterologous host. Science 265:509-512. doi:10. 1126/science. 8036492

Khosla C, Tang Y, Chen AY, Schnarr NA, Cane DE (2007) Structure and mechanism of the 6-deoxyerythronolide B synthase. Annu Rev Biochem 76:195-221. doi:10.1146/annurev.biochem.76.053105. 093515

Koehn FE, Carter GT (2005) The evolving role of natural products in drug discovery. Nat Rev Drug Discov 4:206-220. doi:10.1038/ $\operatorname{nrd} 1657$

Kotowska M, Pawlik K (2014) Roles of type II thioesterases and their application for secondary metabolite yield improvement. Appl Microbiol Biotechnol 98:7735-7746. doi:10.1007/s00253-0145952-8

Kumpfmüller J, Kabisch J, Schweder T (2013) An optimized technique for rapid genome modifications of Bacillus subtilis. J Microbiol Methods 95:350-352. doi:10.1016/j.mimet.2013.10.003

Lambalot RH, Gehring AM, Flugel RS, Zuber P, LaCelle M, Marahiel MA, Reid R, Khosla C, Walsh CT (1996) A new enzyme superfamily - the phosphopantetheinyl transferases. Chem Biol 3:923-936. doi:10.1016/S1074-5521(96)90181-7

Leuschner RGK, Robinson TP, Hugas M, Cocconcelli PS, RichardForget F, Klein G, Licht TR, Nguyen-The C, Querol A, Richardson M, Suarez JE, Thrane U, Vlak JM, von Wright A (2010) Qualified presumption of safety (QPS): a generic risk assessment approach for biological agents notified to the European Food Safety Authority (EFSA). Trends Food Sci Technol 21:425-435. doi:10.1016/j.tifs.2010.07.003

Li J, Jaitzig J, Hillig F, Süssmuth R, Neubauer P (2014) Enhanced production of the nonribosomal peptide antibiotic valinomycin in Escherichia coli through small-scale high cell density fed-batch cultivation. Appl Microbiol Biotechnol 98:591-601. doi:10.1007/ s00253-013-5309-8

Mootz HD, Finking R, Marahiel MA (2001) 4'-phosphopantetheine transfer in primary and secondary metabolism of Bacillus subtilis. J Biol Chem 276:37289-37298. doi:10.1074/jbc.M103556200

Nakano MM, Magnuson R, Myers A, Curry J, Grossman AD, Zuber P (1991) $s r f A$ is an operon required for surfactin production, competence development, and efficient sporulation in Bacillus subtilis. J Bacteriol 173:1770-1778

Panula-Perälä J, Siurkus J, Vasala A, Wilmanowski R, Casteleijn MG, Neubauer P (2008) Enzyme controlled glucose auto-delivery for high cell density cultivations in microplates and shake flasks. Microb Cell Fact 7:31. doi:10.1186/1475-2859-7-31

Patel PS, Huang S, Fisher S, Pirnik D, Aklonis C, Dean L, Meyers E, Fernandes P, Mayerl F (1995) Bacillaene, a novel inhibitor of procaryotic protein synthesis produced by Bacillus subtilis: 
production, taxonomy, isolation, physico-chemical characterization and biological activity. J Antibiot (Tokyo) 48:997-1003. doi:10. 7164/antibiotics.48.997

Petsch D, Anspach FB (2000) Endotoxin removal from protein solutions. J Biotechnol 76:97-119. doi:10.1016/S0168-1656(99)00185-6

Pfeifer BA, Admiraal SJ, Gramajo H, Cane DE, Khosla C (2001) Biosynthesis of complex polyketides in a metabolically engineered strain of E. coli. Science 291:1790-1792. doi:10.1126/science. 1058092

Pfeifer BA, Hu Z, Licari P, Khosla C (2002) Process and metabolic strategies for improved production of Escherichia coli-derived 6deoxyerythronolide B. Appl Environ Microbiol 68:3287-3292. doi:10.1128/AEM.68.7.3287-3292.2002

Sietske de Boer A, Diderichsen B (1991) On the safety of Bacillus subtilis and B. amyloliquefaciens: a review. Appl Microbiol Biotechnol 36: 1-4. doi:10.1007/BF00164689

Silbersack J, Jürgen B, Hecker M, Schneidinger B, Schmuck R, Schweder T (2006) An acetoin-regulated expression system of Bacillus subtilis. Appl Microbiol Biotechnol 73:895-903. doi:10. 1007/s00253-006-0549-5

Stein T (2005) Bacillus subtilis antibiotics: structures, syntheses and specific functions. Mol Microbiol 56:845-857. doi:10.1111/j.13652958.2005.04587.x

Tsuge K, Matsui K, Itaya M (2007) Production of the non-ribosomal peptide plipastatin in Bacillus subtilis regulated by three relevant gene blocks assembled in a single movable DNA segment. J Biotechnol 129:592-603. doi:10.1016/j.jbiotec.2007.01.033
Ukkonen K, Vasala A, Ojamo H, Neubauer P (2011) High-yield production of biologically active recombinant protein in shake flask culture by combination of enzyme-based glucose delivery and increased oxygen transfer. Microb Cell Fact 10:107. doi:10.1186/1475-285910-107

van Dijl JM, Hecker M (2013) Bacillus subtilis from soil bacterium to super-secreting cell factory. Microb Cell Fact 12:3. doi:10.1186/ 1475-2859-12-3

Welsch N, Homuth G, Schweder T (2012) Suitability of different B-galactosidases as reporter enzymes in Bacillus subtilis. Appl Microbiol Biotechnol 93:381-392. doi:10.1007/s00253-011-3645-0

Zeigler DR, Pragai Z, Rodriguez S, Chevreux B, Muffler A, Albert T, Bai R, Wyss M, Perkins JB (2008) The origins of 168, W23, and other Bacillus subtilis legacy strains. J Bacteriol 190:6983-6995. doi:10. 1128/JB.00722-08

Zhang H, Boghigian BA, Pfeifer BA (2010) Investigating the role of native propionyl-CoA and methylmalonyl-CoA metabolism on heterologous polyketide production in Escherichia coli. Biotechnol Bioeng 105:567-573. doi:10.1002/bit.22560

Zhang G, Li Y, Fang L, Pfeifer BA (2015) Tailoring pathway modularity in the biosynthesis of erythromycin analogs heterologously engineered in E. coli. Science Advances 1:e1500077. doi:10.1126/ sciadv. 1500077

Zobel S, Kumpfmüller J, Süßmuth RD, Schweder T (2015) Bacillus subtilis as a heterologous host for the secretory production of the non-ribosomal cyclodepsipeptide enniatin. Appl Microbiol Biotech 99:681-691. doi:10.1007/s00253-014-6199-0 